\title{
Cost Estimation of Cashew Extract Evaporator Using Scaling Factors and Cost Index
}

\author{
${ }^{1}$ Abdulraheem, M.O., ${ }^{2}$ Aberuagba, F., ${ }^{3}$ Okafor, J.O. and ${ }^{4}$ Otaru, A.J. \\ ${ }^{1}$ (99, Amac Health Clinic Road, Zone 6, Lugbe, FCT-Abuja) \\ 2,3\&4 (Department of Chemical Engineering, Federal University of Technology Minna, Nigeria).
}

\begin{abstract}
Lot of accuracy is required in estimating capital investment costs. A tabular form is suggested for estimating total product cost and constitutes a valuable checklist to foreclosed omissions. Using annual profit of $\$ 1,182,340.46$ (\$3,593.74 x 329days). Assumed feed rate of 14,400ltrs; composition cashew source 62.05 per cent, water 37.95per cent. Estimated cost of equipment using scaling factors and cost index, from the equipment Vs capacity exponent, was given as 0.54 and gotten as $\$ 28,159.49$ as at 1990 and calculated as \$109,545.7 in 2013 assumed 9\% inflation to date. The total fixed-capital investment using ranges of process-plant component costs give us \$416,272.96. Where the double effects evaporators was proven to be better. Break-even point, gross earnings, and net profit for the process plant where given thus: The direct production cost/unit is $\$ 0.226$ 'unit, number of units needed for a break-even point (n), is 13,369,609.7units/year. The plant operates at $74 \%$ of the present plant operating capacity. Gross annual earnings is \$286,714.588, Net annual earnings is $\$ 566,227.22$. Pay - back Time, Savings is 1,856,890 units/year with Rate of Return as 74.11per cent and as 1.35years.

Keywords: Cashew, Cost, Evaporator, Extract and Nigeria.
\end{abstract}

\section{Introduction}

The cost estimation which involves capital investment, operation costs and sales of products can be grouped under the general heading of total product cost. The largest sources of error in total-product- cost estimation are overlooking elements of cost. Continuous processes are economical for a large scale production. Batch processes are used where some flexibility is wanted in production rate or product specification. Annual profit at 329days per year was adopted out of 365days in the year, considering holidays and weekends. Assume the feed rate be 14,4001 trs; with composition of cashew source 62.05 per cent and water 37.95 per cent. To estimate the cost of equipment scaling factors and cost index will be used, from the equipment Vs capacity exponent, this is given as 0.54 at $\$ 28,159.49$ in 1990 . The total fixed-capital investment using ranges of process-plant component costs. The investment comparison for required the operation with limited number of choices. The effective effects of evaporators would be determined. Break-even point, gross earnings, and net profit for the process plant would also be calculated. The direct production cost per unit, number of units needed for a break-even point (n), units per year. The plant present operating capacity is put at $74 \%$. Gross annual earnings, Net annual earnings, Pay - back Time, Savings and Rate of return on the investment.

\section{Cashew apple juice extraction}

\section{Research materials and methodolgy}

Cashew fruits, red elongated type is plunged from the isolated tree, carry to the laboratory. The plunged cashew was carefully selected to remove the infected and damaged ones, average weight of a cashew is taken along with the cashew nut and without the nut. The following average weight of the cashew without the nuts was obtained $=82.88 \mathrm{~g}$

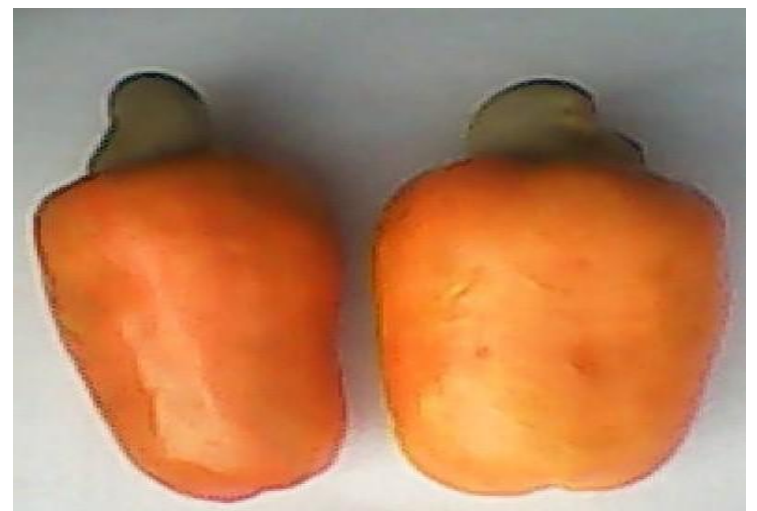

Figure 1. Red elongated Cashew Apple Fruit 


\section{Cashew extract juice modification.}

Rice gruel was used which is another clarifying agent for raw cashew apple juice and is another contribution of Indian research scientists. There are other three agents that can be used also but, rice gruel happened to be the quickest way to obtain clear cashew apple juice - with the simplest of means

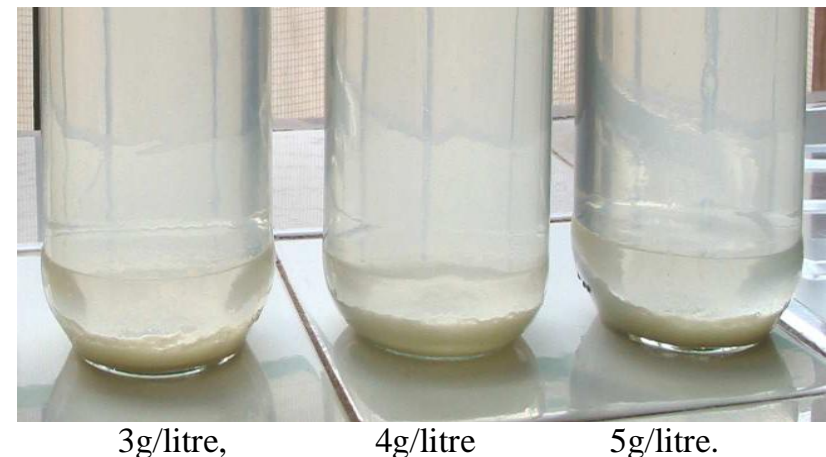

Figure 2. Jars of Cashew with settlement of tannin content

\section{Material balance}

\section{Working design}

A material balance taken over the complete process will determine the quantities of raw materials required and products produced. Balances over individual process units set the process stream flows and compositions. A good understanding of material balance calculations is essential in process design. Material balances are also useful tools for the study of plant operation and trouble shooting. They can be used to check performance against design; to extend the often limited data available from the plant instrumentation; to check instrument calibrations; and to locate sources of material loss. (Coulson \& Richardson, 1998)

\section{Conservation of mass}

The general conservation equation for any process system can be written as: Material out $=$ Material in + Generation - Consumption - Accumulation For a steady-state process the accumulation term will be zero. Mass is neither generated nor consumed; but if a chemical reaction takes place a particular chemical species may be formed or consumed in the process. If there is no chemical reaction the steady-state balance reduces to; ( Wiley, 1978.)

Material out $=$ Material in

Material balance

It is necessary to make a material balance to determine the top and bottoms product flow rates. Balance on cashew, cashew loss in bottoms neglected.

Distillate, (D) water, $80 \%$,

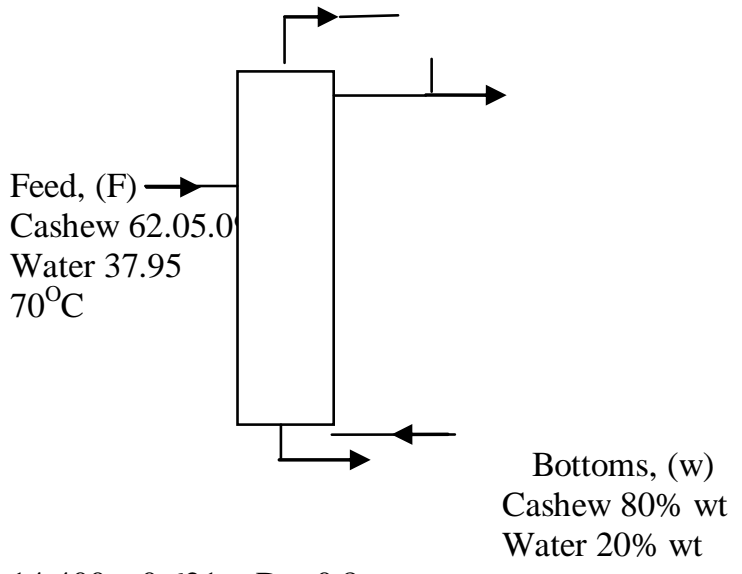

$14,400 \times 0.621=\mathrm{D} \times 0.8$

Distillate, $\mathrm{D}=11,178.4 \mathrm{ltr}$

Bottoms, $\mathrm{W}=14,400-11,178=3,22271 \mathrm{tr}$

Figure 3: Evaporator for the concentration of cashew apple juice 
Annual profits earnings calculation

The total cost of producing a crate, assuming $15 \%$ of the cost production was taken as handling and packaging charges $=$ N1,250.89

Table 1. Present market price of other malt drinks

Brand /Crate Market value/Bottle

\begin{tabular}{lllll}
\hline Maltina $=\mathrm{N} 2,000 \quad \mathrm{~N} 100$ & \multicolumn{1}{c}{ x 24} & & N2,400 \\
High-Malt =N1,900 & N100 & x 24 & N2,400 \\
Nasmalt $=\mathrm{N} 1,750$ & $\mathrm{~N} 100$ & x 24 & N2,400 \\
Mucamalt $=\mathrm{N} 1,600$ & $\mathrm{~N} 80 \times 24$ & N1,920 &
\end{tabular}

Profitability analysis on a crate of Mucamalt

Profit to the company $=$ Sales cost per crate - Cost of production per crate

$\mathrm{N} 1,600-\mathrm{N} 1,250.89=\mathrm{N} 349.11 /$ crate.

While the retailers profit per crate will be $=\mathrm{N} 320.00$

Hence, $160 \mathrm{HL}$ tank which is equivalent to 16,000 litres equals to 2020.2 crates of $33 \mathrm{cl}$ bottle.

Assume the plant is working at $80 \%$ capacity,

Therefore $2020.2 \times 0.8=1,616.16$ crates will be produced per day.

At $\mathrm{N} 1,250.89$ per crate $\times 1,616.16$ crates $=\mathrm{N} 2,021,638.38$

Cost of producing 1,616.16 crates of mucamalt will therefore be

(@ Assume N157 is to a Dollar) = = $\quad=12,876.678$

Supposed a crate of mucamalt is sold for $\$ 10.191$

Therefore, $1,616.16$ crates will cost $=\$ 16,470.42$

Profit per brew on $160 \mathrm{HL}$ per day will be:

$\$(16,470.42-12,876.678)=\$ 3,593.74$

Annual profit at 329days per year $=\$ 3,593.74 \times 329$

$$
=\$ 1,182,340.46
$$

\section{Number of independent components}

A balance equation can be written for each independent component. Not all the components in a material balance will be independent.

\section{Physical systems, no reaction}

If there is no chemical reaction the number of independent components is equal to the number of distinct chemical species present.

\section{Chemical systems, reaction}

If the process involves chemical reaction the number of independent components will not necessarily be equal to the number of chemical species, as some may be related by the chemical equation.

Consider a separation unit, such as a distillation column, which divides a process stream into two product streams. Let the feed rate be 14,4001trs; composition cashew source 62.05 per cent, water 37.95 per cent.

\section{To estimate cost of equipment using scaling factors and cost index.}

The purchased cost of a 227.5litre glass-lined, jacketed reactor (without drive) was $\$ 8,350$ in 1981. Estimate the purchased cost of a similar 13,65litre, glass-lined, jacketed reactor (without drive) in 1990. Using the annual average Marshall and Swift equipment-cost index (process industry) to update the purchase cost of the reactor. Marshall and Swift equipment-cost index (process industry)

For 1981721 and For 1990924 (Plant Design \& Economics for chemical Engineers, M S Peters \& K D Timmerhaus pg " Cost Estimation" Pp 163 )

The equipment Vs capacity exponent is given as 0.54

$$
1990 \text {, Cost of Evaporator }=(\$ 8350)(924 / 721)(1,365 / 227.5)^{0.54}
$$

$$
=\$ 28,159.49
$$

For the cost of 14,400 litres in January $2013=\$ 28,159.49$, equivalent to the cost of 1,365 litres of Hence, 14,400 litres will cost $=\$ 28,159.49(14,400 / 1,365)^{0.54}$

$$
=\$ 100,500.7
$$

Allowing for 9\% inflation from 1990 to 2013, cost 


$$
=\$ 100,500.7 \times(1.09)=\$ 109,545.7
$$

Estimate a fixed-capital investment using ranges of process-plant component costs.

A fixed-capital investment for a process plant for a purchased-equipment cost of $\$ 109,545.7$ Processplant component cost outlined in 167 for a process plant handling fluids with a high degree of automatic controls and essentially outdoor operation is used with lowest range.

(Plant design \& economic for chemical engineers, Timmerhaus, cost estimation pp 167) Table 2. Cost of individual components for the fixed capital investment

\begin{tabular}{|c|c|c|}
\hline Components Assumed\% of tota & Cost & Ratio\% of total \\
\hline Purchased equip. 15 & $\$ 109,545.7$ & 26.3 \\
\hline \multicolumn{2}{|l|}{ Purchased-equip. install. $643,818.28$} & 10.5 \\
\hline Instrumentation (installed) 2 & 14,606 & 3.5 \\
\hline Piping (installed) & 21,909 & 5.3 \\
\hline Electrical (installed) & 14,606 & 3.5 \\
\hline Buildings (including serv.) 3 & 21,909 & 5.3 \\
\hline Yard improvements & 14,606 & 3.5 \\
\hline Service facilities (installed) 8 & $58,424.37$ & 13.8 \\
\hline 7,303 & 1.75 & \\
\hline Engineering and superv. 429,212. & & 7.0 \\
\hline Construction expense $4 \quad 29,212$. & & 7.0 \\
\hline Contractor's fee 2 & 3.5 & \\
\hline $\begin{array}{l}36,515 . \\
\mathbf{\$ 4 1 6 , 2 7}\end{array}$ & & 8.75 \\
\hline
\end{tabular}

$\$ 416,272.96$ for the assumed conditions if economy is stable. However, it may vary within the given range.

Investment comparison for required operation with limited number of choices.

A plant is being designed in which $160 \mathrm{HL}$ per 24 -h day of a cashew juice extract containing $\mathbf{6 2 . 0 5}$ percent by weight is to be concentrated to 30 percent by weight. A single-effect or multiple-effect evaporator will be used, and a single-effect evaporator of the required capacity requires an initial investment of $\$ 416,272.96$ This same investment is required for each additional effect. Let the service life be 14 years, and the salvage value of each effect at the end of the service life $\$ 20,000$. Fixed charges minus depreciation amount to 20 percent yearly, based on the initial investment. Steam costs $\$ 0.60$ per 4,546 litres, and administration, labor, and miscellaneous costs are $\$ 6.688$ per day, no matter how many evaporator effects are used.

Where $\mathrm{X}$ is the number of evaporator effects, $0.9 \mathrm{X}$ equals the number of pounds of water evaporated per pound of steam. There are 329 operating days per year. If the minimum acceptable return on any investment is 15 percent, how many effects should be used?

Basis: 1 operating day

$\mathrm{X}=$ total number of evaporator effects

Depreciation per operating day (straight-line method)

$$
\begin{gathered}
=\frac{X(416,272.96-20,000)}{(14)(329)} \\
=\$ 86.03 / \text { day }
\end{gathered}
$$

Fixed charges - depreciation $=\frac{X(416,272.96)(0.2)}{329}$

$$
=\$ 253.05 / \text { day }
$$

Pounds of water evaporated per day $=$

$$
\begin{aligned}
(1,600,000)(0.625) & (37.95 / 62.05)-(1,600,000)(0.625)(30 / 70) \\
& =611,600-428,5701 \text { tr } / \text { day } \\
& =183,030 \text { ltr/day }
\end{aligned}
$$

Steam costs $=\underline{(183,030)(0.60)}=\$ 26.84$ per day

$\mathrm{X}(\mathrm{O} .9)(4,546)$

$$
\mathrm{X}
$$


Table 3. Investment comparison for required operation

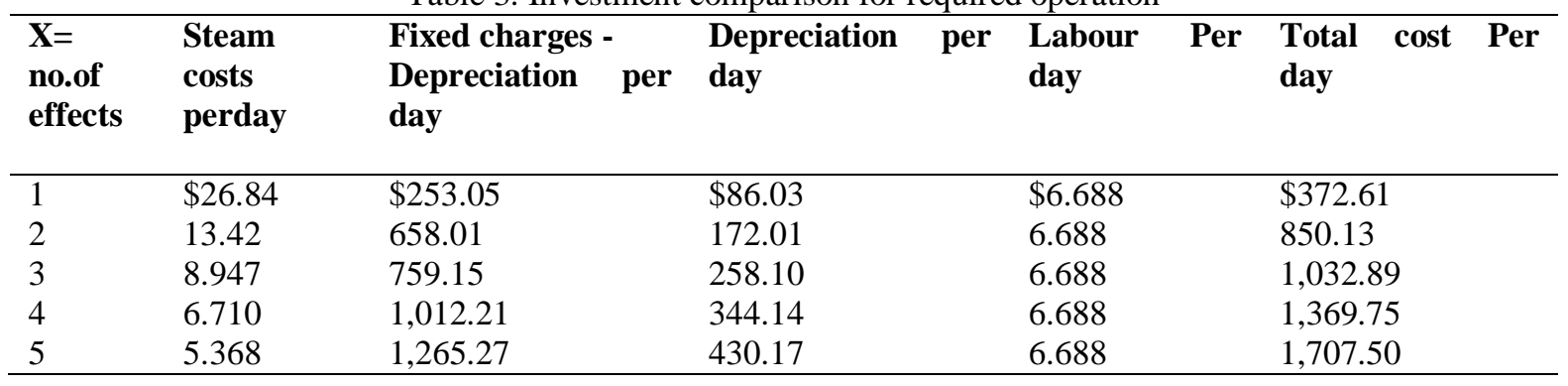

Percent return $=\frac{(372.61)(329)(100)}{416.272 .96}=29.45 \%$

$$
416,272.96
$$

Comparing two effects with one effect,

Percent return $=\frac{(850.13-372.61)(329)(100)}{832,545.92-416,272.96}=37.78 \%$

Comparing three effects with two effects,

Percent return $=\frac{(1,032.89-850.13)(329)(100)}{832,545.92-416,272.96}=14.44 \%$

Comparing four effects with three effects

Percent return $=\underline{(1,369.75-1,032.89)(329)(100)}=26.62 \%$

$$
416,272.96
$$

Comparing five effects with four effects,

Percent return $=\frac{(1,707.5-1,369.75)(329)(100)}{416,272.96}=26.69 \%$

Therefore, two effects are better than one, three, four and five effects.

Since a return of at least 15 percent is required on any investment, all the effects except three effects are good whether single or multiple effects. Two effects evaporator can be maintain because of; 1) Good percentage return on the investment and 2) daily pay which is considerably moderate, which is enough criteria for comparisons on the effects.

\section{Break-even point, gross earnings, and net profit for a process plant.}

The annual direct production costs for a plant operating at 80 percent capacity are $\$ 4,236,427.06$ while the sum of the annual fixed charges, overhead costs, and general expenses is $\$ 847,285.412$. The break-even point in units of production per day if total annual sales are $\$ 5,418,768.18$ and the product sells at $\$ 0.289$ per unit. The annual gross earnings and net profit for this plant at 100 percent capacity in 2013 when corporate income taxes required a 15 percent tax on the first $\$ 50,000$ of annual gross earnings, 20 percent on annual gross earnings of $\$ 50,000$ to $\$ 80,000,30$ percent on annual gross earnings above $\$ 80,000$, and 5 percent on gross earnings from $\$ 100,000$ to $\$ 300,000$

Solution. The break-even point occurs when the total annual product cost equals the total annual sales. The total annual product cost is the sum of the fixed costs (including fixed charges, overhead, and general expenses) and the direct production costs for $\mathrm{n}$ units per year. The total annual sales is the product of the number of units and the selling price per unit.

Thus Direct production cost/unit $=\frac{4,236,427.06}{5,418,768.18 / 0.289)}$

$$
(5,418,768.18 / 0.289)
$$

$$
=\$ 0.226 \text { 'unit }
$$

and the number of units needed for a break-even point is given by $847,285.412+0.226 n=0.289 n$

$$
\begin{aligned}
& \mathrm{n}=\underline{847,285.412}= \\
& 13,369,609.7 \text { units/year } \\
& 0.063
\end{aligned}
$$

This is $[(13,369,609.7) /(14,400,000 / 0.8)] 100=74 \%$ of the present plant operating capacity. 
Gross annual earnings $=$ total annual sales - total annual product cost $=$ (0.289/unit )

$$
\begin{aligned}
& =\quad 5,202,000-[847,285.412+\underline{14,400,000}(\$ 0.226 / \text { unit }) \\
& 0.8 \\
& =\quad 5,202,000-4,915,285.412 \\
& =\$ 286,714.588
\end{aligned}
$$

Net annual earnings $=$ gross annual earnings - income taxes

$$
\begin{aligned}
=847,285.41 & -[(0.15)(50,000)+(0.20)(30,000) \\
& +(0.30)(847,285.41-80,000) \\
& +(0.05)(847,285.41-100,000] \\
& =847,285.41-281,058.19 \\
& =\$ 566,227.22
\end{aligned}
$$

\section{Pay - back Time.}

If the plant is producing $13,369,609.7$ units/y of a product with overall yield of 80 per cent, on a mass basis (litre of product per ltr raw material). The raw material costs $\$ 0.226 /$ unit, and the product sells for $\$ 0.289 /$ unit. If a modification is devised to increase the yield to 90 per cent. Assume the net annual earnings of $\$ 566,227.22$ is to be re- invested back into the business, with negligible operating costs. Will the modification be worth making?

\section{Solution}

Two ways are applicable to earn gain in the modification: 1. If the additional production given by the yield increase can be sold at the current price, the earnings on each additional litre of production will equal the sales price less the raw material cost.

2. If the additional production cannot be readily sold, the modification results in a reduction in raw material requirements, rather than increased sales, and the earnings (savings) are from the reduction in annual raw material costs.

The second way gives the lowest figures and is the safest basis for making the evaluation.

At 13,369, 609.7 units/y production

Raw material requirements at 80 per cent yield

$$
=13,369,609.7 / 0.8=16,712,012
$$

At 90 per cent yield $=13,369,609.7 / 0.9=14,855,122$

Savings 1,856,890 units/year

Cost savings, at $\$ 0.226 /$ litre, $=1,856,890 \times 0.226$

$$
=\$ 419,657.14 / \text { year }
$$

Rate on return $(\mathrm{ROR})=(419,657.14 / 566,227.22) 100$

$$
=74.11 \text { per cent }
$$

Pay-back time (as the annual savings are constant, the pay-back time is the reciprocal of the Rate of return )

$$
=100 / 74.11=1.35 \text { years }
$$

The modification is worth embarking on.

\section{Cashew apple juice extraction}

\section{Results And Discussion Of Results}

The red elongated cashew average weight obtained without nuts $=82.88 \mathrm{~g}$, Physical and water content of the red elongated cashew apple: Ave. wt., 82.88g, ${ }_{\mathrm{pH}}$ 5.4, Juice cont. 62.05g, Substrate cont. 20.83g, Water cont. $74.87 \%$

\section{Annual profits earnings calculation}

From the grand total cost of N9,345.45 to produced_206.2bottles,(8.6crates) while cost of producing a bottle stood at $\mathrm{N} 45.32$ and crate cost N1,087.73. Assumed $15 \%$ of the cost of production is used as handling and packaging charges, therefore, the cost per crate now will be N1,250.89

Six (6) crates of mucamalt will therefore be,

$=\mathrm{N} 2,021,638.38$ and @ N157 to Dollar $=\$ 12,876.678$

Supposed a crate of mucamalt is sold for N1,600 (\$10.191) per crate

Therefore, 1,616.16 crates will cost $(1,616.16 \times 1,600)$ 
$=\$ 16,470.42$

Profit per brew on 160HL per day will be:

$\$(16,470.42-12,876.678)=\$ 3,593.74$

Annual profit at 329days per year $=\$ 3,593.74 \times 329=\$ 1,182,340.46$

\section{Estimating the cost of equipment using scaling factors and cost index.}

Using the annual average Marshall and Swift equipment-cost index (process industry) to update the purchase cost of the reactor.

From Table 5, the equipment Vs capacity exponent is given as 0.54

1990, Cost of Evaporator $=(\$ 8350)(924 / 721)(1,365 / 227.5)^{0.54}$

$$
=\$ 28,159.49
$$

To estimate the cost of 14,400litres in January 2013,

14,400 litres will cost, $\$ 28,159.49(14,400 / 1,365)^{0.54}$

$$
=\$ 100,500.7
$$

Allowing for 9\% inflation from 1990 to 2013 , cost $=\$ 100,500.7 \times(1.09)=\$ 109,545.7$

Using the cost of $\$ 109,545.7$ obtained above to calculate for the fixed capital investment with ranges of process - plant component costs. Fixed capital investment with ranges of process-plant component costs was obtained as $\$ 416,272.96$ for the assumed conditions with stable economy. This capital can vary within the given range.

On the investment comparison for required operation with limited number of choices, two effects $(37.78 \%)$ are better than one(29.45\%), three(14.44\%), four(26.62\%) and five(26.69\%) effects respectively.

Since a return of at least 15 percent is required on any investment, all the effects except three effects are good whether single or multiple effects. Two effects evaporator can be maintain because of; 1) Good percentage return on the investment and 2) daily pay which is considerably moderate, which is enough criteria for comparisons on the effects.

\section{Break-even point, gross earnings, and net profit for a process plant at 80 percent}

The direct production cost/unit is $\$ 0.226$ 'unit, the required number of units $13,369,609.7$ units/year while the real operating plant capacity is $74 \%$. The gross annual earnings obtained as $\$ 286,714.588$ and net annual earnings $\$ 566,227.22$ which is not bad at all. Pay - back Time is 1.35 years after re-investment of $\$ 566,227.22$ into the plant, you need 1.35years to pay back which is commendable before profit start to come in and the modification is worth embarking on.

\section{Acknowledgements}

In the name of Allah (SWT), the most beneficent, the most merciful. Glory is to him for his guidance toward the successful completion of this research work

\section{References}

[1]. Anon. (1986) Process Engineering (Jan.) 13. Changing index bases.

[2]. Anon. (1992) Process Engineering (March) 18. Predict indices a review.

[3]. Aries, R. S. \& Newton, R. D. (1955) Cost Estimation (McGraw-Hill).

[4]. Baasel, W. D. (1965) Chem. Eng., NY 72 (Oct. 25th) 147. Exploring response surfaces to establish optimum conditions.

[5]. Baasel, W, D. (1974) Preliminary Chemical Engineering Plant Design (Elsevier).

[6]. Baumol, W. J. (1972). Economic Theory and Operations Analysis, $3^{\text {rd }}$ ed. Prentice Hall, Englewood Cliffs, New Jersey

[7]. Bechtel, L. B. (1960) Chem. Eng., NY 67 (Feb. 22nd) 127. Estimate working capital needs.

[8]. Chilton, C. H. (1960) Cost Engineering in the Process Industries (McGraw-Hill).

[9]. Chopey, N. P. (eel.) Handbook of Chemical Engineering Calculations (McGraw-Hill,1984).

[10]. Coulson \& Richardson's . K. S. (1999) Chemical Engineering Design, Vol. $63^{\text {rd }}$ ed.

[11]. Cran, J. (1973) Process Engineering (Jan.) 18. Process Engineering indices help estimate the cost of new plant.

[12]. Feider, R. M. \& Rousseau, R. W.(1978) Elementary Principles of Chemical Processes (Wiley)

[13]. Garrett, D. E. (1989) Chemical Engineering Economics (Van Norstrand Reinhold).

[14]. Guthrie, K. M. (1969) Chem. Eng., NY 76 (March 24th) 114. Capital cost estimating.

[15]. Happle, J. \& Jordan, D. G. (1975) Chemical Process Economics, 2nd ed. (Marcel Dekker).

[16]. Henley, E. J. \& Rosen, E. M. (1969) Material and Energy Balance Computations (Wiley).

[17]. Icheme (1988) A New Guide to Capital Cost Estimation 3rd ed. (Institution of Chemical Engineers, London).

[18]. Karbanda, O. P. (1978) Process Plant and Equipment Cost Estimating (Sevak Publications, Bombay).

[19]. Levenspiel, O. (1999) Chemical reaction engineering, 3rd ed.

[20]. Perry, R. H. \& Green, D. W. (eds) (1984) Perry's Chemical Engineers Handbook, $6^{\text {th }}$ ed. (McGraw-Hill)

[21]. Pikulik, A. \& DIAZ, H. E. (1977) Chem. Eng., NY 84 (Oct. 10th) 106. Cost estimating for major process equipment.

[22]. Scott, R, (1978) Eng. and Proc. Econ., 3 105. Working capital and its estimation for project evaluation.

[23]. Sterbacek, Z., Biskup, B. \& Tausk, P. (1979) Calculation of Properties Using Corresponding-state Methods (Elsevier).

[24]. Whitwell, J. C. \& Toner, R. K. Conservation of Mass and Energy (McGraw-Hill, 1969).

[25]. Wilson, G. T. (1971) Brit. Chem. Eng. 16 931. Capital investment for chemical plant 